\title{
Trichoscopic Signs in Dermatomyositis, Systemic Lupus Erythematosus, and Systemic Sclerosis: A Comparative Study of 150 Patients
}

\author{
Kumutnart Chanprapaph ${ }^{\mathrm{a}}$ Preeyachat Limtong ${ }^{\mathrm{a}}$ Pintip Ngamjanyaporn ${ }^{\mathrm{b}}$ \\ Poonkiat Suchonwanit ${ }^{a}$ \\ aDivision of Dermatology, Department of Medicine, Faculty of Medicine, Ramathibodi Hospital, Mahidol University,

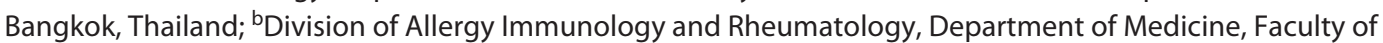 \\ Medicine, Ramathibodi Hospital, Mahidol University, Bangkok, Thailand
}

\section{Keywords}

Alopecia - Connective tissue diseases - Dermoscopy .

Scleroderma $\cdot$ Systemic lupus erythematosus

\begin{abstract}
Background: Hair and scalp involvement is prevalent in connective tissue diseases (CTDs). Trichoscopic features may provide a diagnostic implementation and enable differentiation among CTDs; however, a direct comparison of these signs among CTD patients is lacking. Objectives: To compare trichoscopic findings in dermatomyositis (DM), systemic lupus erythematosus (SLE), and systemic sclerosis (SSC) as well as determine their distinctive features and associations with disease activity. Methods: Trichoscopic photographs were taken from DM, SLE, and SSc patients and further evaluated for hair shaft and scalp surface abnormalities. Data regarding patients' clinical manifestations, laboratory results, and disease activity were analyzed. Results: One hundred fifty participants, consisting of $30 \mathrm{DM}, 60 \mathrm{SLE}$, and $60 \mathrm{SSc}$ patients, were included. Perifollicular red-brown pigmentation, brown scattered pigmentation, and white patches were exclusive findings in DM, SLE, and SSc, respectively ( $p<$ 0.001). A multinomial logistic regression analysis revealed that DM demonstrated higher odds for having microaneurysmal blood vessels than SLE and SSc (odds ratio [OR] =
\end{abstract}

22.22, $95 \%$ confidence interval $[\mathrm{Cl}]=1.73-285.13, p=0.017$, and $\mathrm{OR}=15.34,95 \% \mathrm{Cl}=1.36-177.59, p=0.029$, respectively). Polymorphic vessels forming a telangiectatic network suggested SSc over SLE $(\mathrm{OR}=12.83,95 \% \mathrm{Cl}=1.35-121.98$, $p=0.026)$, while avascular areas were more pronounced in SSc than DM and SLE $(\mathrm{OR}=43.24,95 \% \mathrm{Cl}=5.17-361.67, p=$ 0.001 , and $\mathrm{OR}=0.03,95 \% \mathrm{Cl}=0.01-0.24, p=0.001$, respectively). In a quantile regression analysis, perifollicular redbrown pigmentation, reduction in hair diameter, and the absence of thin arborizing vessels were linked to higher disease activity in DM, SLE, and SSc, respectively (all $p<0.05$ ). Conclusions: Trichoscopy is a valuable tool possessing diagnostic and prognostic values for CTDs. Specific trichoscopic features allow adequate distinction between DM, SLE, and SSc and may help identify active disease.

$$
\begin{aligned}
& \text { C } 2021 \text { The Author(s) } \\
& \text { Published by S. Karger AG, Basel }
\end{aligned}
$$

\section{Introduction}

Hair and scalp changes are common in patients with connective tissue diseases (CTDs) and negatively impact the patients' quality of life, yet they remain largely underrecognized $[1,2]$. Scalp abnormalities in dermatomyositis (DM) have variable frequency (28-82\%), with scaly erythematous pruritic eruption being the most common karger@karger.com www.karger.com/drm

Karger $\stackrel{\text { ' }}{5}$

BOPEN ACCESS
(C) 2021 The Author(s)

Published by S. Karger AG, Basel

This is an Open Access article licensed under the Creative Commons Attribution-NonCommercial-4.0 International License (CC BY-NC) (http://www.karger.com/Services/OpenAccessLicense), applicable to the online version of the article only. Usage and distribution for commercial purposes requires written permission.
Correspondence to:

Poonkiat Suchonwanit, poonkiat@hotmail.com 
manifestation [3-7]. Alopecia in systemic lupus erythematosus (SLE) can be scarring or nonscarring with prevalence ranging from 17 to $85 \%$ [5, 8-11]. Localized scleroderma (e.g., morphea) involving the scalp has been well described; however, information on scalp abnormalities for the generalized form is sparse [1].

The distinction among CTDs can be difficult in patients with skin-predominant disease and has been anchored on the presence of pathognomonic features. However, widely recognized pathognomonic/characteristic cutaneous findings in DM, SLE, and systemic sclerosis (SSc) have been documented in approximately one third to three fourths of these cases [12-15]. Trichoscopy is a noninvasive device widely used on various hair and scalp disorders [16-18]. Trichoscopic abnormalities can be presented in CTD patients even without visible signs; therefore, information on their distinctive features may be of great value for those with a diagnostic dilemma.

Although trichoscopy may provide diagnostic clues for CTDs, only a few studies have exhibited this information $[7,19,20]$. A direct comparison of the trichoscopic findings among the most common CTDs, namely DM, SLE, and SSc, and their relations to the disease activity is lacking. This study aims to evaluate and compare trichoscopic findings among DM, SLE, and SSc patients without noticeable scalp lesions, as well as determine their association with the disease activity.

\section{Materials and Methods}

\section{Study Design}

This is a cross-sectional, analytic study approved by the Mahidol University Institutional Review Board for Ethics in Human Research (MURA2018/589). The study was conducted following the Helsinki Declaration, and written informed consent was obtained from patients before enrollment.

\section{Study Participants}

We enrolled patients from Rheumatology and Dermatology Clinics, Ramathibodi Hospital, Bangkok, Thailand. The inclusion criteria were patients aged $\geq 18$ years with the diagnosis of DM according to the classification of Bohan and Peter [21] and/or Sontheimer [22] and/or the European League against Rheumatism (EULAR)/American College of Rheumatology (ACR) 2017 classification criteria for adult and juvenile idiopathic inflammatory myopathies [23], or SLE defined by the Systemic Lupus International Collaborating Clinics 2012 Criteria [24] and/or the EULAR/ACR 2019 criteria [25], or SSc as stated according to the ACR/EULAR 2013 classification criteria for SSc [26]. Exclusion criteria were overlapping autoimmune diseases, scarring alopecia, other hair and scalp disorders, systemic conditions or using medications affecting hair growth cycle/color, and hair dying in the past month.

\section{Data Collection}

Baseline patient characteristics (i.e., age, disease onset/duration, gender, cutaneous and extracutaneous manifestations) and laboratory results were recorded. The disease activity was assessed by using physician global activity, Cutaneous Assessment ToolBinary Method (CAT-BM) activity score [27], and Manual Muscle Test (MMT) for DM [28]. The SLE Disease Activity Index 2000 (SLEDAI-2K) score was used for SLE [29], and the modified Rodnan Skin Score (mRSS) was applied for SSc [30].

We performed trichoscopic examination using a DermLite DL4 dermoscope (3Gen Inc., San Juan Capistrano, CA, USA) with minimal pressure, and photographs were taken from multiple areas of the scalp by one investigator. Trichoscopic evaluation was made on two aspects comprising the hair shaft and scalp surface. Hair shaft changes included decreased hair number ( single-hair follicles $>20 \%$ of follicles), decreased hair diameter (diameter diversity $>20 \%$ of hair), and hair shaft hypopigmentation (hypopigmentation $\geq 20 \%$ of hair) [7, 31]. Scalp changes comprising black dots, yellow dots, white dots, white patches, brown honeycomb pigmentation, brown scattered pigmentation, peripilar sign, follicular red dots, follicular red-brown pigmentation (red-brown macule around the hair follicle), and blue-gray pigmentation (speckled or target pattern), were noted. Scales were identified as perifollicular and/or interfollicular scales.

We further assessed for vascular abnormalities using a videodermoscope (Dino-Lite Pro; AnMo Electronics Corp., New Taipei City, Taiwan). Characteristics of arborizing vessels were described as thin arborizing blood vessels (vessel diameter thinner than that of terminal hair shafts), prominent arborizing blood vessels (thin vessels forming a vascular network), and thick arborizing blood vessels (vessel diameter larger than that of terminal hair shafts) $[19,32,33]$. Other distinctive vascular patterns, including microaneurysmal blood vessel (linear, serpentine, or tortuous dilated capillary with an ectatic portion resembling an aneurysm), dotted vessels, hairpin vessels, and polymorphic vessels forming a telangiectatic network (PVTN; different pattern of vessels forming a network of telangiectasia), were documented $[20,32]$. Finally, avascular areas (whitish areas of fibrosis with the absence of blood vessels) were evaluated [20]. All trichoscopic photographs taken were assessed by one blinded hair specialist.

\section{Statistical Analysis}

Data analyses were performed using Stata 14.0 (Stata Corp. LLC, College Station, TX, USA). The sample size was estimated based on data from previous studies regarding trichoscopy of CTDs, and a minimum of 26 subjects per group was required [7, $19,20]$. Categorical variables were expressed as counts and percentages. Continuous variables were demonstrated in mean \pm standard deviation (SD) or median (interquartile range, IQR). Analysis of variance, $\chi^{2}$, and Fisher's exact tests were used to compare variables between groups as appropriate. Multinomial logistic regression analysis was applied to estimate odds ratios (ORs) of having a disease of interest and their corresponding 95\% confidence intervals (CIs). Quantile regression analysis was performed to determine the association between trichoscopic signs and disease activity. A $p$ value $<0.05$ was considered statistically significant. 
Table 1. Demographic data and comparison of trichoscopic findings among patients with dermatomyositis, systemic lupus erythematosus, and systemic sclerosis

\begin{tabular}{|c|c|c|c|c|}
\hline Variables & $\mathrm{DM}(n=30)$ & $\operatorname{SLE}(n=60)$ & $\operatorname{SSc}(n=60)$ & $p$ value \\
\hline Age (mean $\pm S D)$, years & $52.0 \pm 16.2$ & $36.7 \pm 14.4$ & $53.8 \pm 12.8$ & n.a. \\
\hline Sex, $n(\%)$ & & & & n.a. \\
\hline Female & $22(73.3)$ & $58(96.7)$ & $50(83.3)$ & \\
\hline Age of disease onset (mean $\pm S D$ ), years & $48.2 \pm 15.8$ & $27.0 \pm 12.9$ & $45.0 \pm 13.9$ & n.a. \\
\hline Median duration of disease (IQR), months & $36(7-60)$ & $90(24-204)$ & $96(36-144)$ & n.a. \\
\hline \multicolumn{5}{|l|}{ Hair shaft findings } \\
\hline Decrease in number & $9(30)$ & $20(33.3)$ & $25(41.7)$ & 0.475 \\
\hline Decrease in diameter & $1(3.3)$ & $10(16.7)$ & $10(16.7)$ & 0.101 \\
\hline Hair shaft hypopigmentation & $3(10)$ & $18(30.0)$ & $0(0)$ & $<0.001^{*}$ \\
\hline \multicolumn{5}{|l|}{ Follicular opening and dots } \\
\hline Black dots & $2(6.7)$ & $2(3.3)$ & $1(1.7)$ & 0.487 \\
\hline Brown honeycomb pigmentation & $24(80.0)$ & $46(76.7)$ & $51(85.0)$ & 0.506 \\
\hline Brown scattered pigmentation & $0(0)$ & $9(15.0)$ & $0(0)$ & $<0.001^{*}$ \\
\hline Blue-gray speckled pigmentation & $12(40.0)$ & $17(28.3)$ & $2(3.3)$ & $0.014^{*}$ \\
\hline Salt and pepper appearance & $0(0)$ & $0(0)$ & $3(5.0)$ & 0.061 \\
\hline White patches & $0(0)$ & $0(0)$ & $25(41.7)$ & $<0.001^{*}$ \\
\hline Perifollicular scales & $20(66.7)$ & $23(38.3)$ & $18(30.0)$ & $0.004^{*}$ \\
\hline Interfollicular scales & $13(43.3)$ & $20(33.3)$ & $11(18.3)$ & $0.031^{*}$ \\
\hline \multicolumn{5}{|l|}{ Vascular findings } \\
\hline Dotted vessels & $8(26.7)$ & $13(21.7)$ & $0(0)$ & $<0.001^{*}$ \\
\hline Thin arborizing vessels & $29(96.7)$ & $60(100)$ & $55(91.7)$ & $0.027^{*}$ \\
\hline Prominent arborizing vessels & $7(23.3)$ & $31(51.7)$ & $22(36.7)$ & $0.026^{*}$ \\
\hline Thick arborizing vessels & $16(53.3)$ & $22(36.7)$ & $31(51.7)$ & 0.169 \\
\hline
\end{tabular}

DM, dermatomyositis; IQR, interquartile range; n.a., not applicable; SD, standard deviation; SLE, systemic lupus erythematosus; SSc, systemic sclerosis. * Statistically significant at $p<0.05$.

\section{Results}

Comparison of Trichoscopic Features among CTDs

One hundred fifty participants, comprising $30 \mathrm{DM}, 60$ SLE, and 60 SSc patients, were included. Their demographics are demonstrated in Table 1. Characteristic trichoscopic changes of DM, SLE, and SSc are illustrated in Figures 1-3, respectively. Hair shaft hypopigmentation was observed in both DM and SLE, but not in SSc, with a significant difference in favor of SLE $(p<0.001)$. Perifollicular red-brown pigmentation, brown scattered pigmentation, and white patches were exclusive findings in DM, SLE, and SSc, respectively (all $p<0.001$ ). Blue-gray speckled pigmentation was found more frequently in both DM and SLE than SSc $(p=0.014)$. Perifollicular and interfollicular scales were seen more often in DM compared to both SLE and SSc ( $p=0.004$ and $p=0.031$, respectively).

Microaneurysmal vessels were exclusive for DM, while the PVTN and avascular areas were distinctive signs of SSc patients. Dotted vessels were more predominant in both DM and SLE than SSc $(p<0.001)$. Thin arborizing vessels forming prominent arborized vascular networks were prevalent in SLE $(p=0.026)$. Any vascular abnormalities located interfollicularly were more prominent in SLE $(p=0.008)$, while perifollicular changes favored DM $(p=0.006)$. Trichoscopic findings of all groups are summarized in Table 1. 


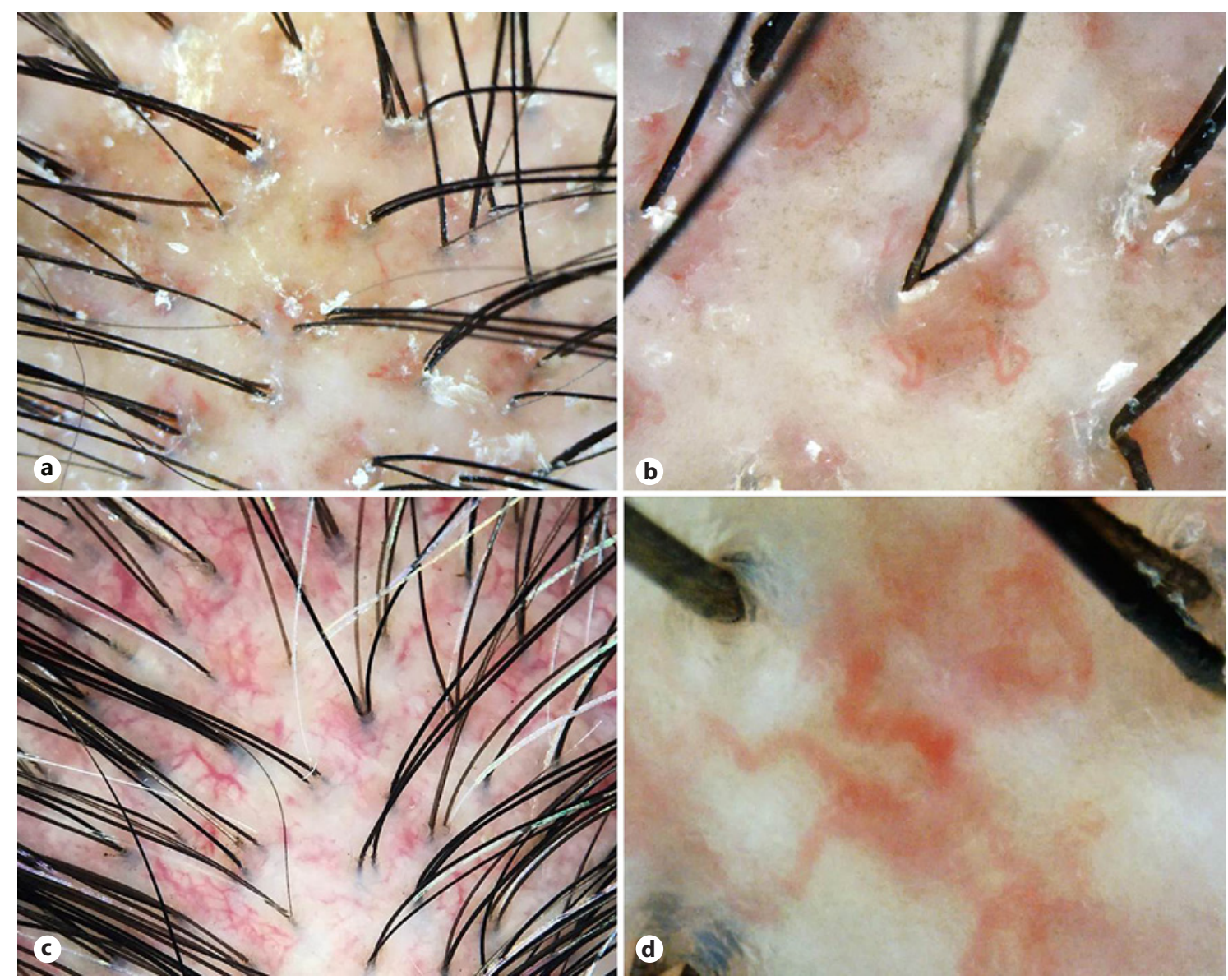

Fig. 1. Trichoscopic features of patients with dermatomyositis. a Perifollicular red-brown pigmentation and scales. $\times 40$. b High magnification of perifollicular red-brown pigmentation showing tortuous blood vessels and brown macules at perifollicular areas. $\times 120$. c Dilated aberrant blood vessels. $\times 20$. d Aneurysmal blood vessels defined as linear, serpentine, or tortuous dilated capillary with an ectatic portion resembling an aneurysm. $\times 200$.
Diagnostic Value of Trichoscopic Features for CTDs

Table 2 demonstrates the diagnostic value of trichoscopy among the three CTDs determined by multinomial logistic regression analysis. For hair shaft features, DM had lower odds for decreased hair diameter than both SLE and SSc (OR $=0.06,95 \% \mathrm{CI}=0.01-0.72, p=0.027$, and $\mathrm{OR}=0.08,95 \% \mathrm{CI}=0.01-0.82, p=0.034$, respectively). Hair shaft hypopigmentation revealed lower odds for both DM and SSc than SLE (OR $=0.15,95 \% \mathrm{CI}=0.02-$ $0.93, p=0.042$, and $\mathrm{OR}=0.04,95 \% \mathrm{CI}=0.01-0.33, p=$ 0.003 , respectively).

Scalp surface features revealed higher odds of perifollicular red-brown pigmentation for DM over SLE and SSc $(\mathrm{OR}=20.61,95 \% \mathrm{CI}=1.71-249.16, p=0.017$, and $\mathrm{OR}=$ 26.41, 95\% CI $=2.68-259.86, p=0.005$, respectively). Brown scattered pigmentation favored SLE over SSc $(\mathrm{OR}=0.05,95 \% \mathrm{CI}=0.01-0.66, p=0.023)$. Blue-gray speckled pigmentation supported both DM and SLE over SSc $(\mathrm{OR}=3.59,95 \% \mathrm{CI}=1.16-11.11, p=0.026$, and $\mathrm{OR}=0.22,95 \% \mathrm{CI}=0.06-0.71, p=0.012$, respectively). White patch demonstrated a stronger association for SSc compared to other CTDs $(\mathrm{OR}=0.04,95 \% \mathrm{CI}=0.01-0.35$, $p=0.004$, and $\mathrm{OR}=25.73,95 \% \mathrm{CI}=3.02-218.98, p=$ 0.003 , respectively). The presence of scales favored DM over both SLE and SSc. While perifollicular scales were more predominant in DM than both SLE and SSc (OR = $3.50,95 \% \mathrm{CI}=1.09-11.22, p=0.032$, and $\mathrm{OR}=4.70,95 \%$ $\mathrm{CI}=1.67-13.24, p=0.003$, respectively), interfollicular scales possessed higher odds for DM than SSc only $(\mathrm{OR}=4.35,95 \% \mathrm{CI}=1.46-12.94, p=0.008)$.

Regarding microvascular abnormalities, DM demonstrated higher odds for microaneurysmal blood vessels than SLE and SSc $(\mathrm{OR}=22.22,95 \% \mathrm{CI}=1.73-285.13$, $p=0.017$, and $\mathrm{OR}=15.34,95 \% \mathrm{CI}=1.36-177.59, p=$ 

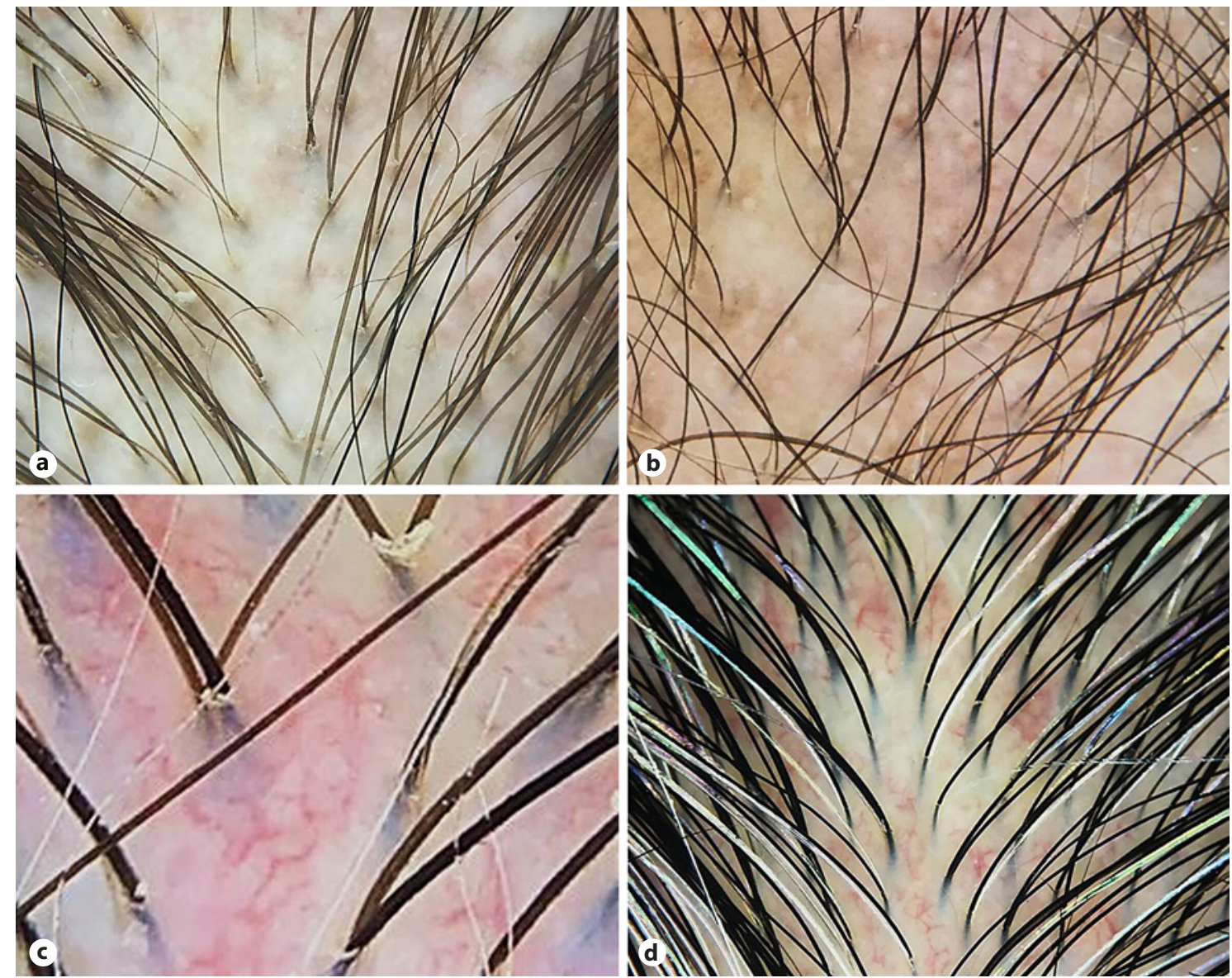

Fig. 2. Trichoscopic features of patients with systemic lupus erythematosus. a Hair shaft changes including decreased hair number, decreased diameter, and hypopigmented hair shafts. $\times 20$. $\mathbf{b}$ Scalp changes consisting of black and white dots, brown scattered pigmentation, and blue-gray speckled pigmentation. $\times 20$. c Prominent arborizing blood vessels forming a vascular network at interfollicular areas. $\times 120$. d Thick arborizing blood vessels. $\times 20$.
0.029 , respectively). Dotted vessels favored both DM and SLE over SSc $(\mathrm{OR}=15.50,95 \% \mathrm{CI}=1.72-139.73, p=$ 0.015 , and $\mathrm{OR}=0.08,95 \% \mathrm{CI}=0.01-0.74, p=0.027$, respectively). PVTN suggested SSc over SLE (OR $=12.83$, $95 \% \mathrm{CI}=1.35-121.98, p=0.026)$, while the presence of avascular areas was more predominant in SSc than DM and SLE $(\mathrm{OR}=43.24,95 \% \mathrm{CI}=5.17-361.67, p=0.001$, and $\mathrm{OR}=0.03,95 \% \mathrm{CI}=0.01-0.24, p=0.001$, respectively).

\section{Association between Trichoscopic Features and}

Disease Activity

In quantile regression analysis, perifollicular redbrown pigmentation was linked to higher physician global activity (coefficient $=40,95 \% \mathrm{CI}=10.40-69.60, p=$ 0.01 ) and CAT-BM activity (coefficient $=3,95 \% \mathrm{CI}=$ $0.04-5.96, p=0.047$ ) scores in DM patients; however, no significant association was demonstrated in the MMT score. For SLE, decreased hair diameter was linked to a higher SLEDAI-2K score (coefficient $=5,95 \% \mathrm{CI}=2.21$ $7.79, p=0.001$ ), while the absence of thin arborizing vessels was related to a higher $\mathrm{mRSS}$ score (coefficient $=-11$, $95 \% \mathrm{CI}=-19.71$ to $2.29, p=0.014$ ) in SSc (Table 3).

\section{Discussion}

The present study provides new insights into trichoscopic values of patients with DM, SLE, and SSc. To our knowledge, we are the first to compare trichoscopic features among these conditions. We have identified distinctive findings on the hair shaft and scalp surface that can adequately differentiate among them. A combination of findings may contribute to their distinction. Moreover, 


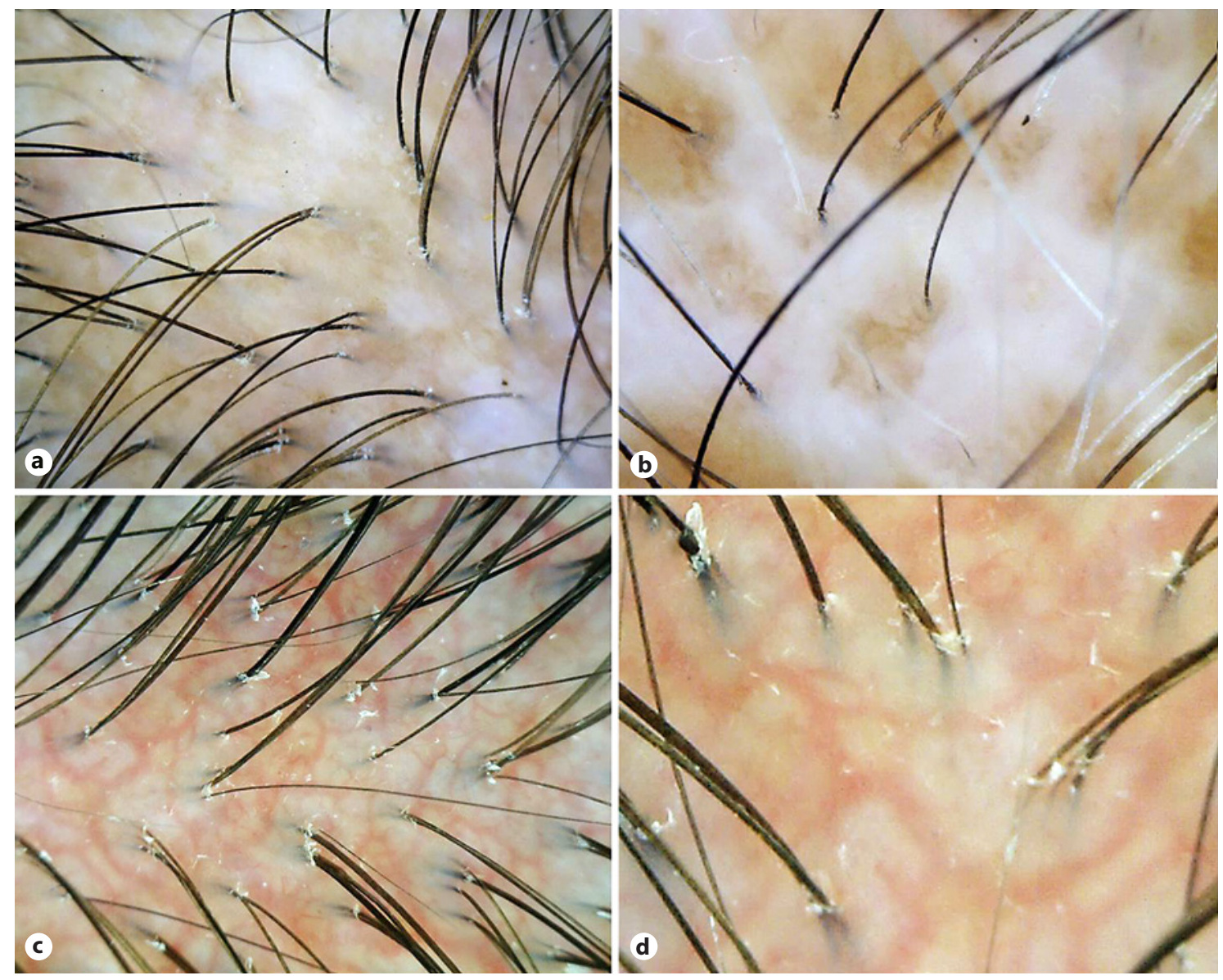

Fig. 3. Trichoscopic features of patients with systemic sclerosis: variable hair shaft and scalp changes including decreased hair number and diameter, avascular areas (a), and white patches (b). $\times 40$. c Polymorphic vessels forming a telangiectatic network de- fined as a different pattern of vessels forming a network of vascular telangiectasia. $\times 40$. d High magnification of polymorphic vessels forming a telangiectatic network. $\times 80$. trichoscopic features may provide prognostic implementations. Table 4 displays trichoscopic signs that can be useful to determine the diagnosis and prognosis of DM, SLE, and SSc.

In DM, although hair shaft changes were subtle, many characteristic scalp surface features were predominant. Perifollicular red-brown macules were distinctive and exclusive for DM (Fig. 1a, b). Blue-gray speckled pigmentation was demonstrated in almost half of the patients. Scales were presented in nearly three fourths of the cases and the perifollicular location favored DM over other CTDs. Our findings were roughly in line with the literature [7]. Under the microscope, blue-gray speckled pigmentation signifies melanophages in the papillary dermis caused by the typical interface dermatitis. Vascular ectasia, endothelial damage, and perifollicular inflammation admixed with features of postinflammatory hyperpig- mentation may represent the characteristic perifollicular red-brown pigmentation $[6,34]$. Scalp DM shows changes in the stratum corneum (e.g., focal parakeratosis) accounting for the scales presented on trichoscopy [6]. Essentially, we have demonstrated that scalp DM possesses abnormalities outside the follicles and preferentially on the perifollicular areas. Our findings correspond to a recent histological study revealing that the follicular architecture is virtually preserved in DM. The minimal follicular insult may also explain minor hair shaft changes observed on trichoscopy in DM patients.

In SLE, Suchonwanit et al. [19] have documented that trichoscopy can provide diagnostic implementation, as their distinctive findings were absent or minimally presented in the normal scalp. The present study confirms the value of trichoscopy beyond that of SLE diagnosis and that characteristic features could be accounted for to dif- 
Table 2. Multinomial logistic regression analysis of trichoscopic findings in patients with dermatomyositis, systemic lupus erythematosus, and systemic sclerosis

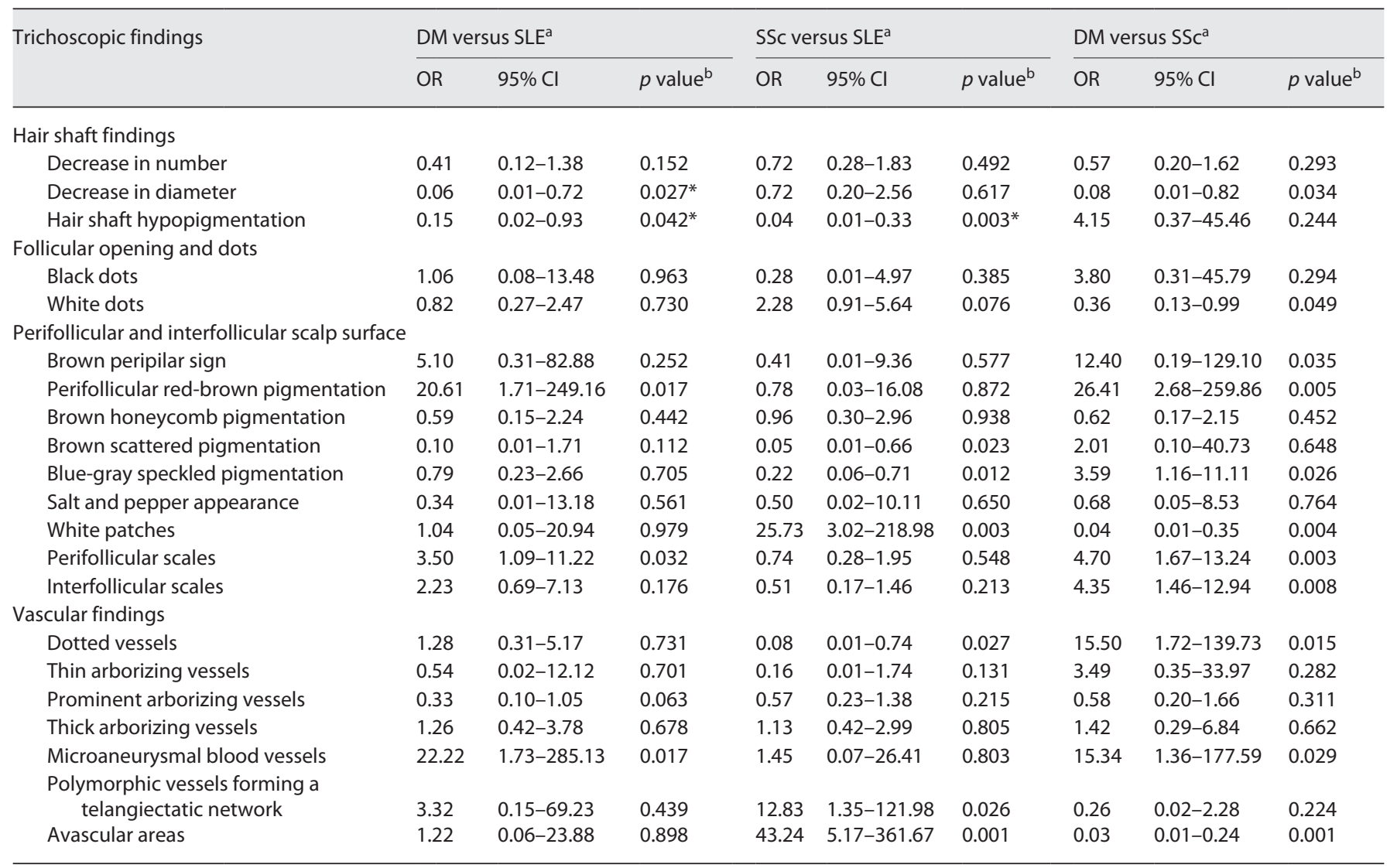

$\mathrm{Cl}$, confidence interval; DM, dermatomyositis; OR, odds ratio; SLE, systemic lupus erythematosus; SSc, systemic sclerosis. Statistically significant at $p<$

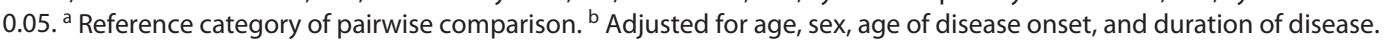

Table 3. Quantile regression analysis of trichoscopic findings in patients with dermatomyositis, systemic lupus erythematosus, and systemic sclerosis

\begin{tabular}{|c|c|c|c|c|}
\hline \multirow[t]{2}{*}{ Disease } & \multirow[t]{2}{*}{ Disease activity score } & \multicolumn{2}{|c|}{ Correlations with disease activity } & \multirow[t]{2}{*}{$p$ value } \\
\hline & & coefficient & $95 \% \mathrm{Cl}$ & \\
\hline \multirow[t]{3}{*}{ DM } & Physician global activity score & & & \\
\hline & $\begin{array}{l}\text { Perifollicular red-brown pigmentation } \\
\text { CAT-BM activity score }\end{array}$ & 40 & $10.40-69.60$ & 0.010 \\
\hline & Perifollicular red-brown pigmentation & 3 & $0.04-5.96$ & 0.047 \\
\hline \multirow[t]{2}{*}{ SLE } & SLEDAI-2K score & & & \\
\hline & Decrease in hair diameter & 5 & $2.21-7.79$ & 0.001 \\
\hline \multirow[t]{2}{*}{ SSC } & mRSS score & & & \\
\hline & Thin arborizing vessels & -11 & -19.71 to -2.29 & 0.014 \\
\hline
\end{tabular}

CAT-BM, Cutaneous Assessment Tool - Binary Method; Cl, confidence interval; DM, dermatomyositis; IQR, interquartile range; mRSS, modified Rodnan Skin Score; OR, odds ratio; SLEDAI-2K, Systemic Lupus Erythematosus Disease Activity Index 2000; SLE, systemic lupus erythematosus; SSc, systemic sclerosis. Statistically significant at $p<$ 0.05 .

Trichoscopic Signs in Connective Tissue Diseases
Dermatology 2022;238:677-687

DOI: $10.1159 / 000520297$ 
Table 4. Comparison of trichoscopic clues for the diagnosis of dermatomyositis, systemic lupus erythematosus, and systemic sclerosis

\begin{tabular}{|c|c|c|c|}
\hline Hair shaft findings & Decreased hair density and diameter & $\begin{array}{l}\text { Prominent hair shaft hypopigmentation } \\
\text { Decreased hair density and diameter }\end{array}$ & $\begin{array}{l}\text { Decreased hair density and } \\
\text { diameter }\end{array}$ \\
\hline Scalp surface findings & $\begin{array}{l}\text { Perifollicular red-brown pigmentation } \\
\text { Blue-gray speckled pigmentation } \\
\text { Prominent perifollicular scales } \\
\text { Prominent interfollicular scales }\end{array}$ & $\begin{array}{l}\text { Brown scattered pigmentation }{ }^{a} \\
\text { Blue-gray speckled pigmentation }\end{array}$ & White patches ${ }^{a}$ \\
\hline $\begin{array}{l}\text { Features related to higher } \\
\text { disease activity }\end{array}$ & Perifollicular red-brown pigmentation & Decreased hair diameter & Absence of thin arborizing vessels \\
\hline
\end{tabular}

DM, dermatomyositis; SLE, systemic lupus erythematosus; SSc, systemic sclerosis. ${ }^{a}$ The most specific sign in differentiating from the others.

ferentiate SLE from its mimickers. Typical trichoscopic findings for SLE were hair shaft changes (decreased hair density/diameter, and hair shaft hypopigmentation) (Fig. 2a) and scalp changes (brown scattered and bluegray speckled pigmentation) (Fig. 2b). Unlike DM, pathology involving follicular architecture (decrement of follicular counts and terminal-to-vellus hair ratio) is remarkable in SLE [35]. Hair shaft alterations could indicate damaged hair matrix cells resulting in defective hair shaft formation and melanogenesis $[8,19,36]$. SLE commonly involves nonfollicular structures as well. Histologically, nonscarring alopecia in SLE demonstrates epidermal atrophy and interface dermatitis along the dermoepidermal junction/follicular epithelium which correspond to brown scattered and blue-gray speckled pigmentation on trichoscopy, respectively [10,35].

SSc involves complex interrelations between the immunological, vascular, and fibrotic elements, resulting in chronic and progressive tissue fibrosis [37]. SSc has long been considered to have no specific scalp and/or trichoscopic changes [38]. However, our study has demonstrated several trichoscopic abnormalities that corresponded well to SSc pathophysiology and were highly suggestive of SSc. Thick homogenized sclerotic collagen bundles in the dermis may compromise the follicular architecture leading to hair size reduction and diffuse hair loss (Fig. 3a) [38]. White patches located between normally arranged follicular units are a visible sign of fibrosis and microcirculation insufficiency in SSc (Fig. 3b) [20]. Unlike DM and SLE, SSc does not possess melanophages as a consequence of interface changes; therefore, the absence of blue-gray speckled pigmentation was anticipated.
The scalp is a well-vascularized structure, and microvascular injury plays a role in the pathophysiology of CTDs. Therefore, vascular abnormalities were universally observed on trichoscopy in over $90 \%$ of all three conditions. Disease-specific microvascular pathology may lead to pattern-specific findings and enables trichoscopic distinction among CTDs. In DM, microvascular pathology is mediated by the humeral process, leading to vascular depletion, hypoxia, and myofiber necrosis. Subsequently, local angiogenesis occurs as a compensation process $[34,39$, 40]. Angiogenic factors (e.g., vascular endothelial growth factor and angiogenin) may involve in the pathogenesis of $\mathrm{DM}$ and correspond to thick arborizing and microaneurysmal blood vessels presented on trichoscopy (Fig. 1c, d) [34, 39-41]. Moreover, the perifollicular location of these aberrant vessels favors DM over both SLE and SSc. In SLE, arborizing blood vessels of the scalp were mostly located interfollicularly and were prominent in size (Fig. 2c, d). Angiogenesis in SLE is induced by raised circulating angiogenic cytokines as well [42]. Despite the shared angiogenetic process, different levels of microvascular injury may lead to phenotypic variation between DM and SLE. Crowson and Magro [34] demonstrated that, compared to SLE, DM lesions showed greater endothelial injury, vascular ectasia, and vascular fibrin deposit. Likewise, we have observed that trichoscopic microvascular features were more aberrant in patients with DM than SLE.

Endothelial injury is the initial vascular insult in SSc, remarkably demonstrating endothelial cell apoptosis, vasoconstriction, and vasculopathy [43]. Tissue hypoxia and fibrosis may parallel the predominant avascular areas and the absence/decrement of normal trichoscopic vas- 
cular structures. Angiogenesis also appears in SSc as compensation to chronic hypoxia, but the process may be defective and dysregulated and could evolve towards various forms of neovascularization. The characteristic trichoscopic finding, the PVTN (Fig. 3c, d), has also been described by Jasso-Olivares et al. [7] and may be a consequence of defective angiogenesis in SSc. Nevertheless, future studies on pathomechanism, biomarkers, and their effects on different morphology and pattern of vascular abnormalities in CTDs are warranted.

We are the first to identify the association between trichoscopic features and validated tools in measuring disease activity in DM and SSc. Our data affirm that decreased hair diameter paralleled a higher SLEDAI-2K score and may be related to an inflammatory process damaging the hair matrix cells in patients with SLE [19]. The presence of perifollicular red-brown macules indicated higher physician global activity and CAT-BM scores in DM, reflecting both microvascular changes and scalp inflammation. Increased levels of type 1 interferon, a group of cytokines accountable for inflammatory responses and vascular changes, were associated with higher disease activity in both DM and SLE [44-49]. We have also demonstrated that the absence of thin arborizing blood vessels was linked to a higher mRSS score in SSc. As a well-vascularized structure, thin arborizing vessels are a common trichoscopic finding in the normal scalp [19]; once progressive rarefaction of microvessels occurs in SSc, extensive tissue fibrosis becomes apparent. Loss of vascular structures can be further linked to progressive skin thickening measured via the mRSS score [15]. Nevertheless, further large prospective studies are required to verify these findings.

The limitation of our study includes its cross-sectional, single-center nature, which allowed no follow-up period and restricted the study population to Southeast Asians. Additionally, our sample size was relatively small.

\section{Conclusion}

Careful attention to specific trichoscopic features enables distinction between DM, SLE, and SSc. Decreased hair diameter was suggestive for SLE and SSc, while hair shaft hypopigmentation indicated SLE. Perifollicular redbrown macules, brown scattered pigmentation, and white patches were exclusive for DM, SLE, and SSc, respectively. Blue-gray speckled pigmentation supported DM and SLE, while scales favored DM. Microaneurysmal vessels and avascular areas were restricted to DM and SSc, re- spectively. Certain trichoscopic changes hold prognostic values for CTDs. Perifollicular red-brown pigmentation, reduction in hair diameter, and the absence of thin arborizing vessels were linked to higher disease activity in DM, SLE, and SSc, respectively.

\section{Key Message}

Trichoscopic examination provides diagnostic and prognostic values for dermatomyositis, systemic lupus erythematosus, and systemic sclerosis.

\section{Acknowledgement}

We would like to thank Dr. Adam M. Huber for allowing us to use the Cutaneous Assessment Tool-Binary Methods (CAT-BM) for evaluating dermatomyositis disease activity in this project.

\section{Statement of Ethics}

This study protocol was reviewed and approved by the Mahidol University Institutional Review Board for Ethics in Human Research (MURA2018/589). The study was conducted following the Helsinki Declaration, and written informed consent was obtained from each patient before enrollment to participate in the study and to publish their clinical data and images.

\section{Conflict of Interest Statement}

The authors have no conflicts of interest to declare.

\section{Funding Sources}

The authors received no financial support for this research.

\section{Author Contributions}

K. Chanprapaph and P. Suchonwanit designed and conceptualized the study. K. Chanprapaph, P. Limtong, and P. Suchonwanit performed the data collection. K. Chanprapaph, P. Limtong, P. Ngamjanyaporn, and P. Suchonwanit contributed to the analysis and interpretation of the results. K. Chanprapaph, P. Limtong, and P. Suchonwanit contributed to manuscript writing.

\section{Data Availability Statement}

The data sets used and/or analyzed during the current study are available from the corresponding author on reasonable request. 


\section{References}

1 Cassano N, Amerio P, D'Ovidio R, Vena GA. Hair disorders associated with autoimmune connective tissue diseases. G Ital Dermatol Venereol. 2014 Oct;149(5):555-65.

2 Ferraz LB, Almeida FA, Vasconcellos MR, Faccina AS, Ciconelli RM, Ferraz MB. The impact of lupus erythematosus cutaneous on the quality of life: the Brazilian-Portuguese version of DLQI. Qual Life Res. 2006 Apr; 15(3):565-70.

3 Kasteler JS, Callen JP. Scalp involvement in dermatomyositis. Often overlooked or misdiagnosed. JAMA. 1994 Dec;272(24):1939-41.

4 Tilstra JS, Prevost N, Khera P, English JC 3rd. Scalp dermatomyositis revisited. Arch Dermatol. 2009 Sep;145(9):1062-3.

5 Moghadam-Kia S, Franks AG Jr. Autoimmune disease and hair loss. Dermatol Clin. 2013 Jan;31(1):75-91.

6 Jasso-Olivares J, Diaz-Gonzalez JM, Miteva M. Horizontal and vertical sections of scalp biopsy specimens from dermatomyositis patients with scalp involvement. J Am Acad Dermatol. 2018 Jun;78(6):1178-84.

7 Jasso-Olivares JC, Tosti A, Miteva M, Domínguez-Cherit J, Díaz-González JM. Clinical and dermoscopic features of the scalp in 31 patients with dermatomyositis. Skin Appendage Disord. 2017 Aug;3(3):119-24.

8 Udompanich S, Chanprapaph K, Suchonwanit P. Hair and scalp changes in cutaneous and systemic lupus erythematosus. Am J Clin Dermatol. 2018 Oct;19(5):679-94.

9 Yun SJ, Lee JW, Yoon HJ, Lee SS, Kim SY, Lee JB, et al. Cross-sectional study of hair loss patterns in 122 Korean systemic lupus erythematosus patients: a frequent finding of non-scarring patch alopecia. J Dermatol. 2007 Jul; 34(7):451-5.

10 Gong Y, Ye Y, Zhao Y, Caulloo S, Chen X, Zhang B, et al. Severe diffuse non-scarring hair loss in systemic lupus erythematosus clinical and histopathological analysis of four cases. J Eur Acad Dermatol Venereol. 2013 May;27(5):651-4.

11 Chanprapaph K, Ploydaeng M, Pakornphadungsit K, Mekwilaiphan T, Vachiramon V, Kanokrungsee S. The behavior, attitude, and knowledge towards photoprotection in patients with cutaneous/systemic lupus erythematosus: a comparative study with 526 patients and healthy controls. Photochem Photobiol Sci. 2020 Sep 9;19(9):1201-10.

12 Da Silva DM, Patel B, Werth VP. Dermatomyositis: a diagnostic dilemma. J Am Acad Dermatol. 2018 Aug;79(2):371-3.

13 Chanprapaph K, Tankunakorn J, Suchonwanit $\mathrm{P}$, Rutnin S. Dermatologic manifestations, histologic features and disease progression among cutaneous lupus erythematosus subtypes: a prospective observational study in Asians. Dermatol Ther (Heidelb). 2021 Feb; 11(1):131-47.

14 Chanprapaph K, Tubtieng I, Pratumchat N, Thadanipon K, Rattanakaemakorn P,
Suchonwanit P. Cutaneous, systemic features and laboratory characteristics of late- versus adult-onset systemic lupus erythematosus in 1,006 Thai patients. Lupus. 2021 Apr;30(5): 785-94.

15 Ferreli C, Gasparini G, Parodi A, Cozzani E, Rongioletti F, Atzori L. Cutaneous manifestations of scleroderma and scleroderma-like disorders: a comprehensive review. Clin Rev Allergy Immunol. 2017 Dec;53(3):306-36.

16 Errichetti E, Stinco G. Dermoscopy in general dermatology: a practical overview. Dermatol Ther (Heidelb). 2016 Dec;6(4):471-507.

17 Miteva M, Tosti A. Hair and scalp dermatoscopy. J Am Acad Dermatol. 2012 Nov;67(5): 1040-8.

18 Chanprapaph K, Mahasaksiri T, Kositkuljorn C, Leerunyakul K, Suchonwanit P. Prevalence and risk factors associated with the occurrence of autoimmune diseases in patients with alopecia areata. J Inflamm Res. 2021;14: 4881-91.

19 Suchonwanit P, Udompanich S, Thadanipon $\mathrm{K}$, Chanprapaph K. Trichoscopic signs in systemic lupus erythematosus: a comparative study with 109 patients and 305 healthy controls. J Eur Acad Dermatol Venereol. 2019 Apr;33(4):774-80.

20 Kwiatkowska M, Rakowska A, Walecka I, Rudnicka L. The diagnostic value of trichoscopy in systemic sclerosis. J Dermatol Case Rep. 2016 Nov;10(2):21-5.

21 Bohan A, Peter JB. Polymyositis and dermatomyositis (first of two parts). N Engl J Med. 1975 Feb;292(7):344-7.

22 Sontheimer RD. Dermatomyositis: an overview of recent progress with emphasis on dermatologic aspects. Dermatol Clin. 2002 Jul; 20(3):387-408.

23 Lundberg IE, Tjärnlund A, Bottai M, Werth VP, Pilkington C, Visser M, et al. 2017 European League against Rheumatism/American College of Rheumatology classification criteria for adult and juvenile idiopathic inflammatory myopathies and their major subgroups. Ann Rheum Dis. 2017 Dec;76(12): 1955-64.

24 Petri M, Orbai AM, Alarcón GS, Gordon C, Merrill JT, Fortin PR, et al. Derivation and validation of the Systemic Lupus International Collaborating Clinics classification criteria for systemic lupus erythematosus. Arthritis Rheum. 2012 Aug;64(8):2677-86.

25 Aringer M, Costenbader K, Daikh D, Brinks R, Mosca M, Ramsey-Goldman R, et al. 2019 European League against Rheumatism/ American College of Rheumatology classification criteria for systemic lupus erythematosus. Arthritis Rheum. 2019 Sep;71(9):140012.

26 van den Hoogen F, Khanna D, Fransen J, Johnson SR, Baron M, Tyndall A, et al. Classification criteria for systemic sclerosis: an American College of Rheumatology/European League against Rheumatism collaborative initiative. Ann Rheum Dis. 2013 Nov;72(11): 1747-55.

27 Huber AM, Lachenbruch PA, Dugan EM, Miller FW, Rider LG. Alternative scoring of the Cutaneous Assessment Tool in juvenile dermatomyositis: results using abbreviated formats. Arthritis Rheum. 2008 Mar;59(3): 352-6.

28 Rider LG, Ruperto N, Pistorio A, Erman B, Bayat N, Lachenbruch PA, et al. 2016 ACREULAR adult dermatomyositis and polymyositis and juvenile dermatomyositis response criteria - methodological aspects. Rheumatology (Oxford). 2017 Nov;56(11):1884-93.

29 Gladman DD, Ibañez D, Urowitz MB. Systemic lupus erythematosus disease activity index 2000. J Rheumatol. 2002 Feb;29(2):28891.

30 Khanna D, Furst DE, Clements PJ, Allanore Y, Baron M, Czirjak L, et al. Standardization of the modified Rodnan skin score for use in clinical trials of systemic sclerosis. J Scleroderma Relat Disord. 2017 Jan-Apr;2(1):11-8.

31 Rakowska A, Rudnicka L. Normal values in trichoscopy. In: Rudnicka L, Olszewska M, Rakowska A, editors. Atlas of trichoscopy: dermoscopy in hair and scalp disease. London: Springer; 2012. p. 111-7.

32 Rakowska A, Rudnicka L, Olszewska M, Kurzeja M. Blood vessels. In: Rudnicka L, Olszewska M, Rakowska A, editors. Atlas of trichoscopy: dermoscopy in hair and scalp disease. London: Springer; 2012. p. 95-108.

33 Rakowska A, Slowinska M, Kowalska-Oledzka E, Warszawik O, Czuwara J, Olszewska M, et al. Trichoscopy of cicatricial alopecia. J Drugs Dermatol. 2012 Jun;11(6):753-8.

34 Crowson AN, Magro CM. The role of microvascular injury in the pathogenesis of cutaneous lesions of dermatomyositis. Hum Pathol. 1996 Jan;27(1):15-9.

35 Chanprapaph K, Udompanich S, Visessiri Y, Ngamjanyaporn P, Suchonwanit P. Nonscarring alopecia in systemic lupus erythematosus: a cross-sectional study with trichoscopic, histopathologic, and immunopathologic analyses. J Am Acad Dermatol. 2019 Dec; 81(6):1319-29.

36 Seyahi E, Seyahi N, Fresko I, Kuyumcu M, Yazici H. Hair diameter in systemic lupus erythematosus. Lupus. 2006;15(5):282-4.

37 Stern EP, Denton CP. The pathogenesis of systemic sclerosis. Rheum Dis Clin North Am. 2015 Aug;41(3):367-82.

38 Nanda S, De Bedout V, Miteva M. Alopecia as a systemic disease. Clin Dermatol. 2019 NovDec;37(6):618-28.

39 Dalakas MC. Inflammatory muscle diseases. N Engl J Med. 2015 Apr 30;372(18):1734-47.

40 Miossi R, de Souza FHC, Shinjo SK. Nailfold capillary changes in adult new-onset dermatomyositis: a prospective cross-sectional study. Clin Rheumatol. 2019 Sep;38(9):231926. 
41 Chanprapaph K, Fakprapai W, Limtong P, Suchonwanit P. Nailfold capillaroscopy with USB digital microscopy in connective tissue diseases: a comparative study of 245 patients and healthy controls. Front Med (Lausanne). 2021;8:683900.

42 Liu J, Wang X, Yang X, Yan Q, Wang S, Han $\mathrm{W}$. Investigating the role of angiogenesis in systemic lupus erythematosus. Lupus. 2015 May;24(6):621-7.

43 Cutolo M, Soldano S, Smith V. Pathophysiology of systemic sclerosis: current understanding and new insights. Expert Rev Clin Immunol. 2019 Jul;15(7):753-64.
44 Baechler EC, Bauer JW, Slattery CA, Ortmann WA, Espe KJ, Novitzke J, et al. An interferon signature in the peripheral blood of dermatomyositis patients is associated with disease activity. Mol Med. 2007 Jan-Feb; 13(1-2):59-68.

45 Walsh RJ, Kong SW, Yao Y, Jallal B, Kiener PA, Pinkus JL, et al. Type I interferon-inducible gene expression in blood is present and reflects disease activity in dermatomyositis and polymyositis. Arthritis Rheum. 2007 Nov;56(11):3784-92.

46 Huard C, Gullà SV, Bennett DV, Coyle AJ, Vleugels RA, Greenberg SA. Correlation of cutaneous disease activity with type 1 interferon gene signature and interferon $\beta$ in dermatomyositis. Br J Dermatol. 2017 May; 176(5):1224-30.
47 Greenberg SA. Dermatomyositis and type 1 interferons. Curr Rheumatol Rep. 2010 Jun; 12(3):198-203.

48 Wenzel J, Zahn S, Bieber T, Tüting T. Type I interferon-associated cytotoxic inflammation in cutaneous lupus erythematosus. Arch Dermatol Res. 2009 Jan;301(1):83-6.

49 Ono N, Kai K, Maruyama A, Sakai M, Sadanaga Y, Koarada S, et al. The relationship between type 1 IFN and vasculopathy in antiMDA5 antibody-positive dermatomyositis patients. Rheumatology (Oxford). 2019 May 1;58(5):786-91. 